\title{
TODOS OS DIREITOS RESERVADOS? A PROTEÇÃO JURÍDICA DOS PERIÓDICOS BRASILEIROS DE LIVRE ACESSO
}

\section{ALL RIGHTS RESERVED? THE LEGAL PROTECTION OF BRAZILIAN OPEN ACCESS JOURNALS}

\author{
${ }^{1}$ Jordan Vinícius de Oliveira \\ ${ }^{2}$ Marcos Vinício Chein Feres
}

\section{RESUMO}

O presente artigo pretende analisar a realidade dos periódicos brasileiros de livre acesso e sua relação com a proteção jurídica. O plano teórico é constituído pelos conceitos de mitologias jurídicas e de viver plenamente a lei. A metodologia consiste em uma análise empíricoqualitativa de dados diretos e indiretos. Tabelas são elaboradas com vistas ao cruzamento dos dados coletados para, então, aplicar-se as regras de inferência. Em síntese, as conclusões são de que o direito esforçou-se para incorporar uma nova perspectiva de proteção autoral no contexto de novos preceitos tecnológicos. Entretanto, o mesmo direito ainda sofre a influência de padrões proprietários.

Palavras-chave: Acesso livre. Copyright. Creative Commons. DOAJ. Periódicos

\begin{abstract}
This paper aims to analyze the reality of the Brazilian open access journals and their connection with legal protection. The theoretical framework consists of both the mythology of law and living lawfully concepts. Methodologically, this research promotes an empirical and qualitative analysis of direct and indirect data. Tables are elaborated so as to cross-referencing the data collected and, thus, apply the rules of inference. To sum up, the conclusion is that the law attempts to internalize a new perspective of copyright protection in the realm of new technological standards. However, this law is still very much influenced by proprietary patterns.
\end{abstract}

Keywords: Copyright. Creative Commons. DOAJ. Journals. Open Access.

\footnotetext{
${ }^{1}$ Mestrando em Direito pela Universidade Federal de Juiz de Fora - UFJF, Minas Gerais, (Brasil). Bolsista DS/CAPES. E-mail: jordanoliveira@ tutanota.com

${ }^{2}$ Doutor em Direito pela Universidade Federal de Minas Gerais - UFMG, Belo Horizonte, (Brasil).

Professor Associado da Universidade Federal de Juiz de Fora - UFJF. E-mail: mvchein@ gmail.com
} 


\section{INTRODUÇÃO}

A presente pesquisa científica visa investigar o contexto jurídico de proteção das criações científicas autorais, divulgadas por meio de periódicos acadêmicos. Em uma sociedade marcada pelo formato físico de divulgação de obras intelectuais, como livros, artigos e periódicos impressos, a revisão do marco normativo de proteção autoral se faz necessária diante dos novos contextos tecnológicos, onde as mídias e os conteúdos passam a ser digitalizados.

A investigação aqui efetuada será de caráter empírico, na qual será indagada a realidade dos periódicos científicos brasileiros de livre acesso e suas respectivas licenças jurídicas. Para tanto, o plano teórico que irá guiar as análises se funda nos conceitos de mitologias jurídicas, de Paolo Grossi, e na noção de viver plenamente a lei, de Zenon Bankowski.

No item 2 serão elucidadas a metodologia e a concepção teórica adotada, bem como serão levantadas, por meio da análise dos marcos jurídicos e de revisão da literatura técnica, algumas discussões sobre a vigência dos direitos autorais e sua relação com os periódicos de divulgação científica. Ainda nesse item, será descrito o processo de coleta dos dados diretos. No tópico 3, núcleo do trabalho, serão apresentados e discutidos os resultados obtidos por meio da análise inferencial dos dados para, por fim, atingir-se a conclusão do estudo.

Em tempos de digitalização de conteúdo científico, em que as bases migraram dos meios físicos para os digitais, cumpre ressaltar o seguinte problema que guiou a análise realizada: como a lógica restritiva da estrutura do direito autoral, ou copyright, previsto na Lei 9.610/98, influencia a produção livre de conhecimento científico no atual contexto brasileiro?

A hipótese construída e reformulada após a coleta dos dados e confirmada ao final é a de que, a partir da ótica teórica adotada, a proteção jurídica de trabalhos científicos é marcada pelos elementos estruturantes e arraigados da propriedade, mas que o próprio direito, por meio do processo de renovação das normas jurídicas, modulou-se aos novos contextos tecnológicos.

\section{METODOLOGIA E MARCO TEÓRICO}

A elucidação do marco teórico e da metodologia possibilitam a clareza acerca do processo de condução da pesquisa científica. O presente trabalho constitui-se em uma 
pesquisa empírica, na qual foram empregados dados da realidade brasileira de periódicos científicos de livre acesso para interpretar os atuais marcos legais que regulam o tema.

Metodologicamente, a estratégia utilizada é composta por uma pesquisa qualitativa de traços de significação (BABBIE, 2007) sobre dados diretos e indiretos, aliada à realização de inferências descritivas e causais (EPSTEIN; KING, 2002).

Conforme Babbie (2007), a análise por traços de significação (unobtrusive research) se constitui pelo levantamento de todos os dados publicamente disponíveis sobre um tema, com a disposição de hipóteses iniciais, seguida pela contraposição dessas hipóteses com dados da realidade fática para, em um terceiro momento, realizar a ressignificação do objeto analisado. Assim, primeiramente foram escolhidas e fichadas fontes bibliográficas sobre o tema de marcos normativos de propriedade intelectual e a respeito de periódicos científicos. Em um segundo momento, foram coletados dados empíricos no âmbito de periódicos de livre acesso e, como terceiro passo, empreendeu-se uma nova interpretação acerca do alcance das normas autorais com o auxílio do marco teórico utilizado.

Essa reinterpretação se complementa com o auxílio das regras de inferência, expostas por Epstein e King (2002). De acordo com os autores, as inferências possibilitam um salto qualitativo na compreensão de fenômenos e podem ser de natureza descritiva, quando se utilizam fatos conhecidos para compreender fatos desconhecidos, ou de natureza causal, quando se utiliza uma variável causal principal e sua decorrência em variáveis dependentes. Para esse artigo, as informações processadas através dos dados de periódicos de livre acesso no Brasil tornam possível, por meio de inferências descritivas e de uma inferência causal, a compreensão do setor de publicação e divulgação científica como um todo, sob o prisma jurídico das licenças autorais adotadas.

Com relação à composição do marco teórico que guia as análises realizadas, se dá pela conjugação da busca de equilíbrio entre lei e amor, contida na noção exposta por Zenon Bankowski (2008) de viver plenamente o direito, aliada à compreensão histórica do direito, presente no conceito de mitologias jurídicas, de Paolo Grossi (2007).

A noção de viver plenamente a lei (BANKOWSKI, 2008) é aqui analisada especialmente no que tange à evolução do direito de tempos em tempos, por meio da interação entre lei e amor. Como se verá ao longo desse trabalho, os periódicos de livre acesso rompem com uma tradição acadêmica, pois desafiam a lógica de restrição dos trabalhos contidos nos periódicos impressos, cujo acesso é limitado. Também fazem cessar uma 
tradição jurídica, pois se utilizam de outra forma de licenciamento que não a clássica proteção do copyright, que viabiliza o controle total da obra autoral pelo seu titular.

Assim, o encaixe da teoria bankowskiana para o presente trabalho se dá pelo fato de que esse novo contexto colaborou para a mudança das próprias normas autorais dos periódicos, o que se revela como um movimento de evolução da proteção jurídica.

O conflito entre lei e amor trabalhado por Bankowski (2008) é, portanto, de central relevância para compreender o atual cenário de divulgação científica. Como as sociedades estão em contínua evolução, os seus respectivos planos normativos passam por processos regulares de renovação para se adequarem aos novos anseios. Esse processo ocorre pela tensão constante entre lei e amor, na qual a lei demonstra os comandos normativos de um sistema, mas que devem estar abertos às situações especiais e o amor, não expressado no sentido romântico, ilustra as aspirações concretas que preenchem de sentido a norma.

Dessa forma é central a interação incessante entre ambos, pois o mero império da lei, sem atenção às aspirações concretas, gera um estado de burocracia perversa, enquanto o reinado único do amor, sem a regularidade normativa, se desdobra em um estado de caos absoluto. Amor e lei são, portanto, dois componentes de uma mesma mistura e em sua reiterada relação conectam as ordens normativas aos ideais de justiça (BANKOWSKI, 2008).

Por sua vez, o conceito de mitologias jurídicas desenvolvido por Grossi (2007) surge da compreensão dos atuais marcos normativos por meio da história do direito. Como os periódicos de livre acesso surgem para romper com uma tradição clássica de restrição de acesso às obras científicas, eles têm de se relacionar com a ordem jurídica vigente, que foi moldada para seguir a mesma lógica restritiva.

Dessa maneira, o encaixe da teoria de Grossi se dá pela compreensão de que certas estruturas jurídicas acabam por afastar o direito do mundo que o cerca, criando certas mitologias, crenças cegas, que passam a ser absolutas no imaginário do jurista, como a de que a proteção jurídica autoral só se dá pela restrição de acesso à obra.

A mitologia jurídica (GROSSI, 2007) se revela como a crítica da passagem dos mecanismos de conhecimento em mecanismos de crença no plano da fundamentação jurídica, de culto à lei por si só. Numa perspectiva histórica, o direito pode ser dividido em dois principais marcos temporais no que tange ao seu ditame: a Era Medieval e a transição para a Modernidade.

Enquanto na ordem jurídica medieval a figura do Príncipe, que representa o Estado, era relegada a segundo plano, o direito era capaz de integrar os fenômenos sociais e se 
expressava como uma realidade histórica. Com isso, Grossi não afirma que o direito da Era Medieval era melhor do que o direito Moderno, mas sim que era horizontalizado, regido pelos usos, ao invés de verticalizado. Contudo, na transição para a Era Moderna, com o uso do direito para a expansão dos impérios, esse Príncipe se agigantou e passou a centralizar a produção dos ditames normativos.

A lei passa a ser dotada de características como generalidade, abstração, rigidez e autoritarismo, pois passa a vir de cima para baixo, de quem controla ou influencia o Estado para quem o compõe. Esses traços, portanto, marcaram profundamente o direito moderno, influenciando-o em sua elaboração e execução e impossibilitando-o de atender plenamente aos anseios concretos no plano de seu uso. Não por acaso, tanto o ensino quanto a aplicação jurídica contemporâneos são marcados por várias abstrações e ficções em sua estrutura, limitando a capacidade crítica e modulatória do jurista e das instituições jurídicas contemporâneas frente aos dilemas sociais, que do direito esperam uma resposta concreta (GROSSI, 2007).

Portanto, a junção dessas teorias serve de baliza para a compreensão do cenário jurídico dos periódicos científicos: ao mesmo tempo em que se encontra em mudança, esse cenário é influenciado pelos clássicos padrões jurídicos já estabelecidos.

Nessa conjuntura, cabe questionar qual o contexto de proteção autoral oferecido pelo direito contemporâneo e, em um segundo momento, estabelecer a sua relação com os periódicos de divulgação científica. Para dar início à primeira tarefa, realiza-se os seguintes questionamentos: o que textos de obras científicas e um sermão têm em comum? Qual o nexo entre uma composição musical sem letra e um dicionário? Ou ainda, o que dizer da relação entre um programa de computador e uma obra litográfica ${ }^{3}$ ? Pois bem, o que une essas diversas categorias de criações intelectuais e outras mais é o fato de que todas são protegidas pelo mesmo direito autoral ou copyright ${ }^{4}$.

A análise do contexto brasileiro de produção intelectual, por intermédio de sua legislação autoral, se justifica pela busca de padrões que compõem e influenciam a realidade dos periódicos científicos, como meios de divulgação de obras autorais. Aqui serão identificadas algumas das mitologias jurídicas expostas por Grossi (2007), sendo assim, a

\footnotetext{
${ }^{3}$ Segundo o dicionário online Michaelis (2016), a litografia é a "arte ou processo de produzir um desenho, caracteres etc. em uma pedra plana, especialmente preparada, e por meio desta reproduzi-los em papel. (...)".

${ }^{4}$ Os exemplos dispostos acima compõem alguns dos treze incisos do artigo $7^{\circ}$ - que trata em rol exemplificativo dos tipos de obras que são protegidas pela lei autoral brasileira - da lei 9.610/98. O que não se encaixa no escopo da lei se encontra no artigo $8^{\circ}$. Com relação aos softwares, são objeto de lei específica, lei 9.609/98, mas abrangidos pelo escopo geral da lei autoral (BRASIL, 1998).
} 
legislação será analisada principalmente no que tange à sua interferência ao acesso e ao uso de obras autorais.

Para tanto, algumas poucas e relevantes disposições contidas na lei brasileira de direitos autorais, Lei 9.610/98, serão brevemente elencadas. Elas estão contidas nos Capítulos III e IV, do Título III da Lei de Direitos Autorais e tratam respectivamente "Dos Direitos Patrimoniais do Autor e de sua Duração" e "Das Limitações aos Direitos Autorais" (BRASIL, 1998). São justamente esses os capítulos que regulam os usos das obras protegidas, estabelecendo o que é possível, no artigo 46, e o que não é possível, no artigo 29 , de se fazer com a obra, sem a expressa autorização do autor.

Desse modo, os artigos 29 e 46 abordam de forma expressa e genérica as restrições à liberdade de acesso e manejo do usuário. As limitadas possibilidades de uso dispostas nos oito incisos do artigo 46, que não violam os direitos patrimoniais do autor, são pouco favoráveis ao cenário científico, que é de criação, divulgação e discussão. Por exemplo, cita-se a possibilidade de reproduzir em um exemplar e, sem intuito de lucro, pequenos trechos de uma obra (inciso II) e a citação, em meios de comunicação, de passagens de uma obra com o intuito de estudo, crítica ou polêmica, desde que indicado o autor original (inciso III). Esses incisos se utilizam de termos como "pequenos trechos" ou "passagens" da obra, sequer permitindo, em termos literais, sua abordagem plena sem a anuência do autor (BRASIL, 1998).

Em contrapartida, o artigo 29 é tão extenso ao dispor sobre as faculdades de controle que o autor possui sobre sua obra, que basta citar o conteúdo de seus incisos IX e X para se mensurar o alcance da lei. O inciso IX dispõe ser vedado, sem autorização prévia e expressa do autor, o armazenamento de conteúdo autoral em um microcomputador e "demais formas de arquivamento". Em termos práticos, isso significa dizer que qualquer mídia de um computador deve ter a autorização expressa de seu respectivo autor ou ter sido adquirida diretamente. Já o inciso seguinte visa se antecipar a futuros eventos, ditando também depender da autorização prévia e expressa do autor "quaisquer outras modalidades de utilização existentes ou que venham a ser inventadas." (BRASIL, 1998, grifo próprio).

Sob a perspectiva teórica de Grossi (2007), é possível constatar, por uma simples análise de poucos dispositivos, o caráter geral, abstrato, rígido e autoritário da legislação brasileira. Em tempos de internet, de microcomputadores e de mídias digitais, onde é possível o compartilhamento instantâneo de conteúdo, a exigência de autorização para qualquer tipo de 
uso revela-se no mínimo impraticável e, no contexto científico, torna-se inibidora em relação ao compartilhamento do conhecimento.

Analisando essas disposições rígidas e pouco adaptadas pela perspectiva de Bankowski (2008), verifica-se que a lei de direitos autorais brasileira se afasta das aspirações que a fizeram surgir, já que os moldes da proteção autoral vigente não se desdobram em incentivo à inovação e à criação, mas de simples monopólio patrimonial sobre um trabalho. Os trabalhos autorais são fruto da criatividade humana e decorrem de um processo de riqueza cultural e de circulação de informações e trocas de experiências, aspectos não contemplados pela lei brasileira, que privilegia o controle máximo do autor.

$\mathrm{Na}$ literatura técnica esse efeito restritivo e inadaptado do direito autoral também já foi observado. Ao discorrer sobre a lógica geral do copyright, Carroll (2007, p. 05) afirma que ele possibilita o controle máximo do autor sobre sua obra e que, no contexto de uma sociedade tecnológica, esse domínio exacerbado gera problemas das mais variadas ordens, projetando na internet um espaço dominado por propriedades e proprietários.

Ola (2015, p. 126) também converge nesse sentido ao apontar que a estrutura legal do copyright concede o direito de exclusão ao proprietário, afastando outros do uso e reuso de suas criações, exceto sob expressa autorização.

Como esses traços legislativos restritivos são padronizados em âmbito internacional, a organização global sem fins lucrativos Creative Commons foi criada em 2001, disponibilizando suas próprias licenças de uso, menos limitadoras, em dezembro do ano seguinte (CREATIVE COMMONS, 2016a, 2016b).

Atualmente são seis os principais tipos de licenças, sendo que todas permitem o compartilhamento do material produzido em qualquer formato, desde que atribuída a autoria original. As licenças são as seguintes: CC-BY (atribuição) - possibilita a adaptação do trabalho autoral por terceiros para qualquer propósito, inclusive comercial; CC-BY-SA (atribuição de compartilhamento igual) - possibilita a adaptação por terceiros para qualquer propósito, inclusive comercial, desde que o novo trabalho se mantenha sob a mesma licença; CC-BY-ND (atribuição sem derivações) - possibilita a utilização comercial do material autoral, mas inviabiliza qualquer adaptação do mesmo; CC-BY-NC (atribuição não comercial) - possibilita a adaptação do material, desde que para fins não comerciais; CC-BYNC-SA (atribuição não comercial de compartilhamento igual) - possibilita a adaptação do material, desde que sob a mesma licença e para afins não comerciais; e CC-BY-NC-ND 
(atribuição não comercial sem derivações) - não possibilita a distribuição comercial do material e inviabiliza qualquer adaptação do mesmo (CREATIVE COMMONS, 2016c).

Acerca das licenças creative commons, Carroll (2007, p. 06) assevera que elas representam uma espécie de "copyright sociável” (conversational copyright), mantendo o direito autoral original sobre a obra, mas assegurando um uso mais justo, por conceber ao usuário um núcleo mais amplo de liberdades.

Em sua análise crítica sobre os commons, Elkin-Koren (2006, pp. 11-3) argumenta que tratar trabalhos criativos por meio de direitos de propriedade é uma prática que reforça a lógica proprietária. Para a autora, o processo criativo é marcado em sua gênese por liberdade e livre fluxo das informações, havendo uma "virtude dialógica" nesse processo constante de troca de experiências. As licenças creative commons, assim, apenas alteram a profundidade do copyright, reforçando, porém, sua influência na vida cotidiana e concebendo trabalhos criativos como mercadorias.

No que tange à lógica proprietária, os alertas trazidos por Elkin-Koren podem até parecer exagerados diante dos contornos ainda mais mercantis do direito autoral. Todavia, empregando-se o enfoque teórico de Grossi (2007, pp. 141-2), constata-se que o grande traço distintivo da civilização burguesa é justamente o ter, amparado na propriedade. Para o autor, a noção proprietária é tão arraigada na sociedade contemporânea que extrapola as fronteiras do mero bem-estar ou do poder, atingindo definitivamente o campo da moral e sacralizando-se.

Aplicando-se também o prisma teórico de Bankowski (2008), observa-se que as licenças creative commons constituem-se como uma tentativa de evolução da legislação para acompanhar os progressos sociais, sendo uma resposta do próprio direito à intransigibilidade deste que o afasta do contexto social.

Com relação aos periódicos científicos, estes se inserem nesse contexto de proteção autoral, podendo optar pelo clássico copyright ou por formas alternativas, como as licenças creative commons. O grande desdobramento é que essa escolha afeta em maior ou menor grau às liberdades de acesso ou ao uso de uma obra divulgada por um periódico científico. Para compreender esse cenário, autores como Shavell (2009) e Ola (2015) foram consultados, sob a justificativa de que abordam os efeitos do direito autoral no âmbito da divulgação científica e dialogam, ainda que indiretamente, com os pressupostos teóricos de busca pelas aspirações da lei e de mitologias jurídicas.

Assim, seria o slogan "todos os direitos reservados" a melhor forma expressão que a proteção jurídica pode conferir para obras de natureza acadêmica? Conforme Shavell (2009, 
p. 02), a resposta é negativa, pois o motivo convencional da aplicação do copyright em trabalhos escritos é o incentivo ao lucro com a venda direta da obra, como com uma mercadoria. Todavia, esse objetivo é insuficiente no contexto acadêmico, já que o escritor visa primariamente à estima científica, ao reconhecimento e ao avanço profissional em vez do lucro.

Assim, o autor sugere a extinção do direito autoral como concebido atualmente no plano de trabalhos acadêmicos, já que esse direito inviabiliza ou restringe o acesso às obras. Com o fim do copyright acadêmico, expõe que as taxas e os custos de publicação poderiam ser subsidiados por universidades e órgãos mantenedores, sendo que tanto os autores quanto os leitores se beneficiariam do livre acesso aos trabalhos científicos.

Ademais, argumenta que a retirada do direito autoral se justificaria pelas suas próprias premissas, já que seu uso deveria ser para promover o progresso das ciências e das artes (SHAVELL, pp. 53-6). Tal constatação de não equivalência de premissas se traduz no insucesso da proteção jurídica de atender às suas aspirações, como visto em Bankowski (2008).

Em sua análise do contexto da Nigéria, como um país do hemisfério sul e à margem dos progressos científicos do norte, Ola (2015) afirma que o atual cenário de publicação e divulgação científica exclui e priva os nigerianos de seu direito básico de acesso ao conhecimento e, a partir dessa premissa, analisa o surgimento do livre acesso.

A consideração desse autor se justifica pelos fatos de que sua análise apreende e aborda as generalidades que a proteção jurídica pode impor e o esforço da lei para se renovar e atender aos novos tempos, como visto respectivamente em Grossi (2007) e em Bankowski (2008). Além disso, sua análise também é revelante por abordar o contexto de um país que, assim como o Brasil, se encontra em um processo de desenvolvimento e em que o acesso a obras por meio de periódicos livres passa a ser utilizado.

Conforme Ola (2015 p. 117), a Nigéria não sofre com a ausência de talentos ou de instituições educacionais e de pesquisa, mas ao cientista nativo são dadas apenas duas possibilidades de divulgação do seu trabalho: em periódicos do próprio país, que sofrem de pequena visibilidade local e global, ou em periódicos globais de acesso geralmente fechado, que impossibilitam o contato local com as obras devido à imposição de altos custos, como taxas de acesso, inviáveis para a população do continente africano.

Desse modo, o autor investiga como alternativa iniciativas como os chamados open access journals, ou periódicos de livre acesso, para contornar a lógica de exclusão do direito 
autoral, que permite ao proprietário o controle total sobre o uso de seus trabalhos. Expõe que, em seu favor, os periódicos de livre acesso possibilitam a difusão de acesso a conteúdo científico, a visibilidade local e global e maior impacto e utilidade para os trabalhos científicos. Em contrapartida, salienta os riscos de uma divisão digital da produção científica, já que o hemisfério sul sofre com desafios de infraestrutura e desenvolvimento, o que geraria uma cultura de consumo de conteúdo do norte, mais do que de contribuição com trabalhos científicos (OLA, 2015, pp. 127-131).

Levantadas essas discussões sob o plano teórico, o item seguinte serve para a compreensão do processo de separação dos dados que serão analisados.

\subsection{Método de Coleta e Sistematização dos Dados}

Como o principal traço distintivo da pesquisa científica de qualidade é a sua replicabilidade (EPSTEIN; KING, 2002), o presente tópico visa elucidar cada etapa de coleta dos dados. As bases de dados diretas consultadas foram o $\mathrm{DOAJ}^{5}$, no qual se obteve informações sobre os 881 periódicos brasileiros de livre acesso indexados até a data limite de 29 de julho de 2016, bem como o respectivo site de cada um desses periódicos por uso de uma pesquisa publicada online, com o intuito de coletar a respectiva licença jurídica de propriedade intelectual e a instituição responsável. Além disso, consultou-se as bases do Ministério da Educação para obter informações acerca das instituições de ensino superior brasileiras para cruzamento dos dados.

O DOAJ (2016) foi escolhido por ser uma base de amplo alcance, presente mundialmente com mais de dois milhões de documentos de livre acesso. Dá-se ênfase que o DOAJ não é a única base de livre acesso existente no mundo, citando-se outras como SSRN, AGORA etc. (OLA, 2016, p. 122), mas certamente é a mais ampla fonte de pesquisa para retratar a realidade brasileira, pois o Brasil é o país com mais periódicos indexados, sendo 881 ao todo. O segundo e o terceiro países com mais periódicos indexados são, respectivamente, Reino Unido, com 752 periódicos e os Estados Unidos com 675 periódicos (DOAJ, 2016).

Nessa base, a pesquisa foi realizada da seguinte maneira: primeiramente foi visitada a página online (vide fim da nota de rodapé 3) do diretório com um navegador devidamente atualizado, clicando-se na aba "Search", localizada ao lado da aba "Home". Após o clique, o

\footnotetext{
${ }^{5}$ Directory of Open Access Journals é um diretório global online de indexação de periódicos de livre acesso, que reúne conteúdo científico de 130 países. Website oficial: 〈https://doaj.org/>.
} 
diretório apresenta os mais de dois milhões de resultados entre periódicos e artigos. No menu à esquerda da página, no campo "Journals vs Articles", foi selecionada a opção "Journals" somente, já que o objetivo do trabalho é investigar a divulgação científica, que se faz por meio de periódicos, sendo exibidos os mais de 9 mil periódicos indexados. Ainda no menu à esquerda da página, foi selecionado o campo "Country of Publisher" e, dos países que surgem, clicou-se na primeira opção: “Brazil". Em seguida foram exibidos os 881 periódicos, coletados um a um entre 31 de junho e 29 de julho de 2016 (DOAJ, 2016).

Muito embora o DOAJ disponha do recurso de mostrar a licença empregada por cada periódico, disponível na opção “Journal License" do menu à esquerda, não se optou por utilizá-la, visto que os dados não estão completos, a saber, a informação não consta para todos os periódicos. Além disso, as licenças informadas não necessariamente condizem com as licenças que atualmente são empregadas pelos periódicos, ocorrendo muitas divergências, motivo que levou à consulta de outra base de dados.

Dessa maneira, a segunda base de dados, utilizada como parâmetro para as licenças jurídicas desses 881 periódicos, foi a coleta realizada por Oliveira e Feres (2016), publicada online em formato de tabela - "Tabela A - Licenças dos Periódicos Brasileiros Indexados no DOAJ". Tal coleta foi direcionada às páginas desses periódicos, sendo contabilizadas individualmente as informações acerca de "Nome do Periódico", "Instituição Responsável”, "Licenciamento", “Acesso em", contendo a data da visita à página do periódico, "Fonte", onde consta o endereço utilizado e "Observação", onde constam divergências e casos especiais.

Quando o periódico possuía página online com o conteúdo disponível e também constava em uma base de artigos (como Scielo, Elsevier...), Oliveira e Feres (2016) adotaram o critério de coleta da licença que constava no site do periódico, onde estão discriminados os termos de direito autoral. Quando o periódico não possuía página online, ou a possuía, mas o conteúdo estava disponível apenas em uma base de artigos, adotaram a licença da base, porquanto é onde há o livre acesso com os artigos indexados livremente. Os campos consultados no site de cada periódico para coletar a informação sobre a licença variam pela diversidade de instituições e padrões de sites, sendo os links mais usuais: "Sobre a Revista", "Capa", "Livre Acesso", "Direitos Autorais" ou pelo número atual da revista, no campo "Atual" de cada periódico. As licenças Creative Commons e Copyright costumam ainda se posicionar no rodapé da página (OLIVEIRA, FERES, 2016). 
Para o presente estudo, aqueles resultados foram compactados e dispostos em três subtabelas, que derivam da tabela original. $\mathrm{Na}$ "Tabela 1" constam informações sobre o número total de licenças por periódicos do DOAJ, após consulta à Tabela A (OLIVEIRA; FERES, 2016), que foi elaborada do período de 31 de junho a 29 de julho de 2016. Quando o site do periódico não informava a licença, adotou-se o rótulo "não informado". Quando informava uma licença creative commons, mas não especificava qual, adotou-se o rótulo "creative commons". Quando a página do site não era carregada, mesmo com acesso em dias alternados, adotou-se o rótulo "Link offline". Ressalta-se ainda que o rótulo genérico "Copyright" adotado por Oliveira e Feres (2016) refere-se ao direito autoral das obras divulgadas ser tanto do periódico quanto do autor, já que boa parte dos periódicos celebrava contrato de cessão de direitos autorais com o autor.

$\mathrm{Na}$ “Tabela 2" foram delimitadas as licenças jurídicas dos periódicos vinculados às chamadas "IESs" (instituições de ensino superior), já que o objetivo do estudo é investigar o licenciamento em periódicos acadêmicos que se relacionam direta ou indiretamente a programas de pós-graduação e são mantidos ou contam com o apoio direto de instituições de ensino superior. Nessas instituições, o objetivo primordial é a promoção e a troca de conhecimento entre a comunidade acadêmica e a sociedade em geral (SHAVELL, 2009).

Assim, a Tabela 2 separa as licenças jurídicas dos periódicos que se vinculam apenas a IESs de natureza ${ }^{6}$ pública ou privada, retiradas da Tabela A, elaborada por Oliveira e Feres (2016). O critério de separação adotado para diferenciar entre público e privado foi o do Ministério da Educação, por meio do serviço online chamado "e-Mec"7 . O procedimento foi o seguinte: visitou-se o website (vide fim da nota de rodapé 5) do órgão governamental, uma vez no site, selecionou-se a aba "Consulta Avançada" na guia central, ao que depois, foram selecionadas as opções "Pública Municipal”, "Pública Federal" e "Pública Estadual", preenchido o campo "Código de verificação" para as IESs de natureza pública. Para as IESs de natureza privada foram selecionados os campos "Privada sem fins lucrativos" e "Privada com fins lucrativos", preenchendo-se em seguida o "Código de verificação". Ambos os resultados foram baixados como planilhas aos 30 dias de julho de 2016, por meio da opção "Exportar Excel”. Voltando à aba "Consulta Avançada", foi selecionada somente a opção

\footnotetext{
${ }^{6}$ Por "pública" entende-se, pelos critérios do MEC, instituições de ensino públicas municipais, federais, estaduais ou as assim delimitadas dentro da categoria "Especial". Por "privada" entende-se instituições privadas sem ou com fins lucrativos ou as assim delimitadas dentro da categoria "Especial" (BRASIL, 2016).

${ }^{7} \mathrm{O}$ e-Mec é a base oficial do governo brasileiro onde constam informações acerca das Instituições de Ensino Superior (IESs) brasileiras ativas e inativas. Website oficial: 〈http://emec.mec.gov.br/>.
} 
"Especial" e baixada ainda a terceira planilha (BRASIL, 2016). Os dados das planilhas do MEC foram cruzados com os da Tabela A, o que possibilitou a criação das subtabelas 2 e 3, onde é que são retratadas a natureza e a licença jurídica dos periódicos.

Por fim, a "Tabela 3" visa estabelecer uma proporção entre o número de instituições de ensino em funcionamento no Brasil e o número de instituições que se vinculam aos periódicos indexados no DOAJ. Essas informações sobre o número total de instituições de ensino foram obtidas com base nas mesmas planilhas do Ministério da Educação à data de referência.

\section{TRAÇANDO INFERÊNCIAS: APRESENTAÇÃO E DISCUSSÃO DE RESULTADOS}

Diante das reflexões empreendidas, parte-se para a investigação do livre acesso no âmbito brasileiro de divulgação científica. Por meio do processo de coleta descrito ao item 2.1 chegou-se à elaboração das três tabelas abaixo apresentadas, que se baseiam em dados obtidos junto ao DOAJ (2016), no site de cada periódico constante na Tabela A (OLIVEIRA; FERES, 2016) e no Ministério da Educação (BRASIL, 2016).

A Tabela 1, abaixo disposta, revela as licenças de 865 dos 881 periódicos indexados no DOAJ. Dezesseis encontravam-se descontinuados ou inativos e por esse motivo não foram contabilizados. Os periódicos offline e os em que a licença não foi informada foram contabilizados à parte, da mesma forma que os periódicos que indicavam o uso de uma licença creative commons, sem especificar qual.

\begin{tabular}{|l|c|}
\hline \multicolumn{2}{|c|}{ TABELA 1 - TIPOS DE LICENÇAS DOS } \\
PERIÓDICOS BRASILEIROS NO DOAJ \\
\hline CC-BY & 416 \\
\hline CC-BY-NC & 139 \\
\hline CC-BY-NC-ND & 98 \\
\hline CC-BY-NC-SA & 22 \\
\hline CC-BY-ND & 01 \\
\hline CC-BY-SA & 10 \\
\hline
\end{tabular}

8 O campo "Especial” foi incluso na pesquisa posteriormente, pois nele são descritas instituições cujo
enquadramento formal ainda será analisado pelo Conselho Jurídico do MEC, mas onde já é possível distinguir a
natureza jurídica pelos dados do sistema. Nessa situação se encontravam duas instituições de natureza pública
com periódicos no DOAJ, aos 30 de julho de 2016: a UNITAU e a FURB, universidades de natureza jurídica
autárquica municipal (BRASIL, 2016). Rev. de Direito, Inovação, Propriedade Intelectual e Concorrência | e-ISSN: 2526-0014 | Curitiba| v. 2 | n. 2 | p. 60 - 80 | Jul/Dez. 2016. 


\begin{tabular}{|l|c|}
\hline Copyright & 148 \\
\hline Creative Commons & 05 \\
\hline Não Informado & 21 \\
\hline Offline & 05 \\
\hline Total & $865^{9}$ \\
\hline
\end{tabular}

Fonte: DOAJ (2016); Tabela A (OLIVEIRA;

FERES, 2016).

Com relação à Tabela 2, amparando-se nos critérios estabelecidos pelo MEC, é investigado o papel das instituições de ensino superior (IESs) nos periódicos de livre acesso contidos no DOAJ. Nessa última base, eram 657 periódicos que se vinculavam a instituições de ensino superior ${ }^{10}$ e 9 periódicos descontinuados ou inativos, que não foram contabilizados.

\section{TABELA 2 - Licenças Jurídicas de Periódicos Vinculados a IESs no DOAJ}

\begin{tabular}{|l|c|c|c|}
\hline Tipos de Licenças & $\begin{array}{l}\text { Número total de } \\
\text { Licenças por IESs }\end{array}$ & $\begin{array}{l}\text { Número Total de } \\
\text { Licenças por IESs } \\
\text { Públicas }\end{array}$ & $\begin{array}{l}\text { Número Total de } \\
\text { Licenças por IESs } \\
\text { Privadas }\end{array}$ \\
\hline CC-BY & 311 & 199 & 112 \\
\hline CC-BY-NC & 105 & 78 & 27 \\
\hline CC-BY-NC-ND & 77 & 55 & 22 \\
\hline CC-BY-NC-SA & 16 & 12 & 04 \\
\hline CC-BY-ND & 01 & 00 & 01 \\
\hline CC-BY-SA & 09 & 04 & 05 \\
\hline Copyright & 118 & 91 & 27 \\
\hline Creative Commons & 03 & 03 & 04 \\
\hline Não informado & 14 & 10 & 01 \\
\hline Offline & 03 & 02 & 203 \\
\hline Total & $657^{11}$ & 454 & 00 \\
\hline Fonte: DOAJ (2016); MEC (BRASIL, 2016); Tabela A (OLIVEIRA; FERES, 2016). \\
\hline
\end{tabular}

9 O número total de periódicos no DOAJ era de 881 até 29/07/16, porém 16 periódicos encontravam-se descontinuados (isto é, não mais ativos) e por isso não foram contabilizados (DOAJ, 2016).

10 Os demais 215 periódicos pertenciam a entidades de variadas naturezas (como associações nacionais, sociedades, editoras particulares, empresas públicas e privadas, colégios públicos, institutos...), não enquadradas como IESs pelo MEC (DOAJ, 2016; BRASIL, 2016).

11 O número total de periódicos vinculados a IESs no DOAJ era de 666 até 29/07/16, porém 9 periódicos encontravam-se descontinuados e por isso não foram contabilizados. Desses, 8 eram vinculados a IESs públicas e 1 era vinculado a uma IES privada (DOAJ, 2016). 
Com relação à Tabela 3, existem dois campos de informações: o referente ao número total de IESs públicas e privadas em território nacional, conforme o MEC e o referente ao número total de IESs públicas e privadas que possuem periódicos no DOAJ. Esses dados possibilitam uma compreensão do quadro de livre acesso por instituições no Brasil.

Tabela 3 - Proporção Nacional de IESs e por Periódicos no DOAJ

Número de IESs em funcionamento Número de IESs e dos respectivos no Brasil periódicos de livre acesso no DOAJ

\begin{tabular}{|l|c|l|c|c|}
\hline IESs & Quantidade & \multicolumn{1}{c}{ IESs } & Quantidade & Periódicos \\
\hline IESs públicas & 315 & Públicas & 80 & 454 \\
\hline IESs privadas & 2.373 & Privadas & 87 & 203 \\
\hline Total de IESs & $2.688^{12}$ & Total de IESs & $167^{13}$ & 657 \\
\hline
\end{tabular}

Fonte: DOAJ (2016); MEC (BRASIL, 2016); Tabela A (OLIVEIRA; FERES, 2016).

Como já ressaltado, o método utilizado para avaliar esses resultados é o de realização de inferências descritivas e causais. As inferências auxiliam, por meio dos dados conhecidos, na compreensão de fenômenos desconhecidos, em um âmbito mais vasto (EPSTEIN; KING, 2002). Dessa maneira, realizam-se abaixo três inferências, de naturezas descritiva e causal.

A primeira inferência, de natureza descritiva, respalda uma constatação negativa no processo de licenciamento de periódicos de livre acesso: o enraizamento da concepção de criações intelectuais como propriedades. Tal inferência se fundamenta na observância da manutenção de certos padrões proprietários em periódicos que têm a natureza de divulgação científica de livre acesso.

Tomando-se por base a classificação das licenças creative commons pela própria organização (CREATIVE COMMONS, 2016d), têm-se as licenças CC-BY e CC-BY-SA como as mais recomendadas para promover mais trabalhos culturais livres. Já as demais quatro licenças, CC-BY-ND, CC-BY-NC, CC-BY-NC-SA e CC-BY-NC-ND são menos propensas para fomentar uma cultura livre, por imporem um maior grau de restrições.

\footnotetext{
${ }^{12}$ Dados retirados do sistema e-Mec (BRASIL, 2016) contabilizando as classes de IESs públicas, privadas e em regime especial à data de 30 de julho de 2016. Dessa última classe, haviam 34 IESs, sendo que 4 estavam classificadas como de natureza privada e 30 de natureza pública.

${ }^{13} \mathrm{O}$ número total de IESs com periódicos no DOAJ é de 168 , das quais 88 são de natureza privada e 80 de natureza pública. Porém, das 88 instituições privadas, apenas 87 possuíam periódicos ativos, sendo que uma não foi contabilizada, pois possuía um único periódico descontinuado (BRASIL, 2016; DOAJ, 2016).
} 
Por esse critério e, adicionando-se a clássica licença de copyright ao rol das licenças mais restritivas, tem-se o significativo número de 408 dos 865 periódicos investigados com licenças menos receptivas para trabalhos culturais livres, conforme a Tabela 1.

O cenário também não é tão divergente no âmbito de periódicos vinculados a instituições educacionais de ensino superior: são 317 de 657 periódicos com licenças de menor abertura de uso, conforme a Tabela 2. Ainda conforme essa tabela, mesmo no âmbito de universidades públicas, que teriam uma maior propensão de compartilhamento e retorno à sociedade dos saberes adquiridos, as licenças mais restritivas somam a marca de 236 de 454 periódicos, ou seja, estão presentes em mais de metade de tais revistas científicas livres.

O embasamento teórico da primeira inferência se dá pela aplicação da perspectiva teórica de Grossi (2007, pp. 68): os números expressivos de periódicos com regras limitadoras revelam mais uma vez a manutenção dos traços proprietários na ordem jurídica moderna. A mitologia jurídica de um direito que concebe suas normas por vias de um horizonte prévio de modelos abstratos e genéricos e que encontra dificuldades para se desvincular deles diante de casos especiais. Como esses modelos jurídicos são criados para uma sociedade de mercado, em que a lógica dominante é a de exploração máxima do lucro e de imposição de restrições a quem não for proprietário, eles não se modulam bem às particularidades do livre acesso.

Desse modo, mesmo nos periódicos livres de instituições públicas de ensino superior, onde o raciocínio primário é diverso do da exploração e obtenção de lucro, o copyright e as quatro licenças creative commons mais restritivas conseguem se proliferar consideravelmente.

Saliente-se que liberdade de acesso é um conceito diverso de licença jurídica. Representa tão somente a liberdade de acessar um conteúdo completo, mas não possibilita qualquer uso adicional sem autorização do autor, assim como no copyright. O fato de um periódico possibilitar a liberdade de acesso demonstra seu desejo de contribuir para uma cultura de liberdade e estima acadêmica, como já mencionado em Shavell (2009), mas a licença jurídica seria um elemento importante para realizar essa aspiração, desde que adequada aos princípios do livre acesso e do compartilhamento de dados.

A segunda inferência é de natureza predominantemente descritiva, mas também causal (EPSTEIN; KING, 2002) e concebe um prisma positivo aos dados observados: a constatação de um número maior de licenças menos restritivas nos periódicos pesquisados demonstra um processo de busca por coerência da norma com o seu uso. Essa inferência é uma consequente lógica oposta da primeira e decorre da constatação de um número 
majoritário de licenças creative commons menos restritivas, CC-BY e CC-BY-SA, nos periódicos de livre acesso.

Como as licenças creative commons são recentes, já que entraram em vigência apenas a partir do ano de 2002, o alto uso notado nos periódicos de livre acesso demonstra a relação de causalidade de que houve uma necessidade de atualização da norma frente à evolução da sociedade. Esse processo pode ser explicado na visão de Bankowski (2008) como a renovação do direito de tempos em tempos, buscando congruência com sua aspiração por meio da cooperação contínua entre lei e amor.

No caso, a lei é representada pela proteção proprietária clássica, que não deve ser descartada, já que possui seu papel em uma sociedade de mercado. Contudo, representando o amor, surgem as aspirações do livre acesso, do reconhecimento acadêmico e da promoção científica, os quais não possuem as razões mercadológicas intrínsecas do clássico direito autoral e se expressam por meio das licenças creative commons menos restritivas.

Essa inferência pode ser ainda complementada teoricamente pela teoria Grossi (2007, pp. 82-3), que aponta a relevância de a lei ser determinada pela sua práxis, sob o risco de rejeição da sociedade. Uma lei que apresenta apenas o copyright como alternativa de uso a todo contexto eleva sua rejeição, dado que a prática social clama por formas de proteção jurídica que se adéquem aos novos tempos.

Enfim, a terceira e última inferência é de caráter descritivo: revela a importância da institucionalização na sedimentação do fundamento das normas. Essa inferência decorre sobretudo da Tabela 3, na qual se vê que um número baixo de instituições é responsável pelos periódicos de livre acesso contidos no DOAJ. São 167 instituições de ensino superior, em um universo total de 2.688, que concentram os periódicos vinculados às IESs brasileiras.

Por meio do enfoque de Bankowski (2008, p. 49), vê-se que a institucionalização é importante para responder ao porquê das regras. Sem a prática institucionalizada e gradativa das instituições e periódicos livres em abandonar o copyright, ainda que esse seja um processo parcial e em construção e de, consequentemente, aderirem a novas formas de licenciamento (como as licenças creative commons), seria impraticável renovar o cenário jurídico da proteção autoral para se adequar ao caso das revistas científicas de livre acesso.

Por conseguinte, realizadas as três inferências, verifica-se que o direito autoral brasileiro possui uma aplicação ampla para restringir as liberdades de uso. A adoção crescente das licenças creative commons por periódicos de livre acesso, contudo, revela-se como um 
fenômeno de busca por um direito menos desconexo com os novos contextos sociais tecnológicos, onde o acesso à informação surge como um direito básico.

Averiguou-se, no entanto, que os dados dos periódicos de livre acesso ainda revelam a existência de traços marcantes da clássica proteção autoral. A constatação de um número significativo de licenças mais restritivas em instituições públicas voltadas para o ensino, pesquisa e extensão é um dado significativo que demonstra isso. Em contrapartida, há de se reconhecer que se percebe um salto gradativo na transição do tradicional copyright para as licenças creative commons, um evento de avanço da ordem jurídica reforçado pela institucionalização de licenças menos restritivas.

Dessa maneira, ao menos no caso dos periódicos científicos de livre acesso, constatase uma nova conjuntura que tende a mudar um velho slogan: todos os direitos não estão mais reservados.

\section{CONSIDERAÇÕES FINAIS}

Esse artigo visou investigar o marco normativo dos periódicos científicos no contexto brasileiro de proteção autoral. Foi realizada uma pesquisa qualitativa de dados diretos e indiretos com vistas a compreender mais de perto a realidade jurídica e institucional do setor.

As análises empreendidas se efetivaram com o auxílio do plano teórico composto pelos ideários de mitologias jurídicas e do viver plenamente a lei. A metodologia de análise partiu de uma pesquisa por traços de significação para a realização de inferências.

Como se trata de uma pesquisa empírica, as fontes diretas de dados foram o diretório de periódicos DOAJ, uma tabela com a respectiva licença e site de cada periódico brasileiro ali indexado por e as bases institucionais do Ministério da Educação acerca das instituições nacionais de ensino superior.

Apurou-se que o contexto legislativo de proteção autoral brasileiro e, em termos mais amplos, o contexto mundial se revelam opressores e desconexos com as necessidades concretas de uso dos atuais tempos digitais.

Verificou-se que as licenças creative commons surgiram no contexto jurídico não para superar o copyright, já que se baseiam em suas mesmas estruturas, mas para amenizar o seu alcance e se aproximar um pouco mais da prática autoral. 
Constatou-se, por meio dos dados diretos analisados, que o plano de periódicos científicos de livre acesso no Brasil busca, gradativamente, superar os traços consolidados do copyright, adotando cada vez mais licenças menos restritivas e que se adéquem à lógica de compartilhamento e reconhecimento profissional a qual perpassa o meio acadêmico. Contudo, faz-se necessário tomar consciência de que as estruturas autorais ainda estão presentes no inconsciente normativo, mesmo no plano de periódicos que prezam pelo livre acesso.

Logo, o presente estudo almeja fornecer dados concretos e contribuir para a discussão da proteção jurídica de periódicos, ressignificando o papel da legislação autoral em vigência. $\mathrm{O}$ objetivo aqui não se trata de desmerecer o direito autoral, visto como ele possui seu lugar e uso específicos em uma sociedade marcada pela propriedade, mas cabe, enfaticamente, desconstruir a concepção de que é a única forma de proteção que o direito deve oferecer.

\section{REFERÊNCIAS}

BABBIE, Earl. The Practice of Social Research. Eleventh Edition . Belmont : Thomson Wadsworth , 2007.

BANKOWSKI, Zenon. Vivendo Plenamente a Lei. Rio de Janeiro: Elsevier Brasil, 2008. 289 p.

BRASIL. E-Mec, v.2.136.0-907. Ministério da Educação. 2016. Disponível em: <http://emec.mec.gov.br/>. Último acesso em 30 de julho de 2016.

BRASIL. Lei 9.610, de 19 de Fevereiro de 1998. Altera, atualiza e consolida a legislação sobre direitos autorais e dá outras providências. 1998. Recuperado em 02 de agosto de 2016, de: <http://www.planalto.gov.br/ccivil_03/leis/L9610.htm>.

CARROLL, Michael W. Creative Commons as Conversational Copyright. Villanova Law/Public Policy Research Paper, $n^{\circ}$. 2007-8. Intellectual Property and Information Wealth: Issues and Practices In The Digital Age, Peter K. Yu, ed., Vol. 1, pp. 445-61, Praeger, 2007. Disponível em SSRN:<http://ssrn.com/abstract=978813>. Acesso em 13 jul. 2016. 
CREATIVE COMMONS. Frequently Asked Questions. 2016a. Disponível em: $<$ https://creativecommons.org/faq/\#what-is-creative-commons-and-what-do-you-do>. Acesso em 03 de julho de 2016.

History. 2016b. Disponível em: <https://creativecommons.org/about/history/>. Acesso em 03 de julho de 2016.

L Licenses and Examples. 2016c. Disponível em: $<$ https://creativecommons.org/share-your-work/licensing-types-examples/licensing-examples/>. Acesso em 02 de julho de 2016.

_. Understanding Free Cultural Works. 2016d. Disponível em: <https://creativecommons.org/share-your-work/public-domain/freeworks/>. Acesso em: 04 de julho de 2016.

DOAJ. Directory of Open Access Journals. Disponível em: <https://doaj.org>. Último acesso em: 29 de julho de 2016.

ELKIN-KOREN, Niva. Creative Commons: A Skeptical View of a Worthy Pursuit. The Future Of The Public Domain. Kluwer Law International. P. Bernt Hugenholtz \& Lucie Guibault (eds), 2006. Disponível em SSRN: <http://ssrn.com/abstract=885466>. Acesso em 03 maio 2016.

EPSTEIN, Lee; KING, Gary. The Rules of Inference. University of Chicago Law Review, Vol. 69, No. 1, 2002. Disponível em: 〈http://gking.harvard.edu/files/rules.pdf〉. Acesso em: 03 de outubro de 2014.

GROSSI, Paolo. Mitologias Jurídicas da Modernidade. Florianópolis: Fundação Boiteaux, 2007. 158p.

LITOGRAFIA (d1). IN: Michaelis Moderno Dicionário da Língua Portuguesa. São Paulo: Editora Melhoramentos Ltda, 2016. Disponível em: $<$ http://michaelis.uol.com.br/busca? $\mathrm{r}=0 \& \mathrm{f}=0 \& \mathrm{t}=0$ \&palavra=litografia $>$. Acesso em 02 de agosto de 2016.

OLA, Kunle. Scholarly Publication in Nigeria: Implications of Open Access. The WIPO 
Journal, (2015) 6. W.I.P.O.J Issue 2.

OLIVEIRA, Jordan Vinícius; FERES, Marcos Vinício Chein. Tabela A - Licenças dos Periódicos Brasileiros Indexados no DOAJ. Data de publicação: Agosto de 2016. Dropbox Inc.: Dropbox. Disponível em: <https://www.dropbox.com/s/sywyk16774ph367/OLIVEIRA\%3B\%20FERES\%2C\%202016.\%20 Tabela\%20A\%20\%E2\%80\%93\%20Licen\%C3\%A7as\%20dos\%20Peri\%C3\%B3dicos\%20Brasilei ros\%20Indexados\%20no\%20DOAJ\%20.pdf?dl=0>. Data de acesso: 02 de Agosto de 2016.

SHAVELL, Steven. Should Copyright of Academic Works be Abolished? Harvard Law School Public Law \& Legal Theory Working Paper Series, Paper No. 10-10, 2009. 